\title{
SURGERY FOR CONGENITAL HEART DISEASE
}

\section{PULMONARY VASCULAR RESISTANCE AFTER CARDIOPULMONARY BYPASS IN INFANTS: EFFECT ON POSTOPERATIVE RECOVERY}

Ingram Schulze-Neick, MD

Jia Li, MD

Daniel J. Penny, MD

Andrew N. Redington, MD
Objective: We sought to define the contemporary clinical effect of increased pulmonary vascular resistance in infants after congenital heart operations with cardiopulmonary bypass.

Methods: Fifteen infants (median age, 0.31 years; median weight, $5.1 \mathrm{~kg}$ ) underwent cardiac operations involving cardiopulmonary bypass (range, 49147 minutes). Pulmonary vascular resistance was measured in the immediate postoperative period in the intensive care unit by means of the direct Fick principle, with respiratory mass spectrometry to measure oxygen consumption. The effect of ventilation with an inspired oxygen fraction of 0.65 , with additional infusion of L-arginine, substance $\mathrm{P}$, and inhaled nitric oxide, was assessed and subsequently correlated with the length of mechanical ventilation from the end of cardiopulmonary bypass to successful extubation.

Results: Overall, pulmonary vascular resistance at baseline $(11.7 \pm 5.6$ $\mathrm{WU} \cdot \mathrm{m}^{2}$ ) could be reduced to a minimum of $6.1 \pm 3.5 \mathrm{WU} \cdot \mathrm{m}^{2}$. The ventilatory time was 0.86 to 14.9 days (median, 1.75 days) and correlated directly with the lowest pulmonary vascular resistance value achieved during the pulmonary vascular resistance study $\left(r^{2}=0.64, P<.01\right)$. The patient subgroup with mechanical ventilation of greater than 2 days had significantly higher pulmonary vascular resistance at all stages of the study protocol, and in this group there was a correlation of cardiopulmonary bypass time and ventilatory support time $\left(r^{2}=0.48, P<.05\right)$.

Conclusion: Increased pulmonary vascular resistance, either directly or as a surrogate of the systemic inflammatory response after cardiopulmonary bypass, continues to have a significant effect on postoperative recovery of infants after cardiac operations. (J Thorac Cardiovasc Surg 2001;121:1033-9)
I children with congenital heart disease, high pulmonary blood flow and pulmonary artery pressure lead to an increase in pulmonary vascular resistance (PVR) preoperatively, which is aggravated by the development of overt pulmonary endothelial dysfunction after cardiopulmonary bypass (CPB). ${ }^{1}$ In some patients the postoperative increase of PVR may be more

From the Cardiothoracic Unit ${ }^{\mathrm{a}}$ and the Cardiac Intensive Care Unit, ${ }^{\mathrm{b}}$ Great Ormond Street Hospital, London, United Kingdom.

Supported in part by a grant from the SPARKS charity (No. 98/BRM/1).

Copyright () 2001 by The American Association for Thoracic Surgery

0022-5223/2001 $\$ 35.00+0 \quad \mathbf{1 2 / 1 / 1 1 3 7 4 7}$

doi: $10.1067 / \mathrm{mtc} .2001 .113747$ marked, may regress slowly, may show intermittent spontaneous or precipitated crisis-like exacerbation, and may require prolonged ventilation and specific strategies to maintain a lower PVR. This is not the case in the majority of patients, in whom, despite demonstrable pulmonary endothelial dysfunction, its clinical manifestations are less obvious. Pulmonary endothelial dysfunction is almost certainly a specific manifestation of a more generalized inflammatory reaction associated with the release of cytokines and other inflammatory mediators after CPB. ${ }^{2}$ It is unclear whether pulmonary endothelial dysfunction itself or as a surrogate of this systemic inflammatory response syndrome may influence postoperative recovery, however. Furthermore, the evolution of surgical algorithms to perform corrective 
Table I. Patient data, clinical course, and PVR

\begin{tabular}{clccccc}
\hline Patient No. & Diagnosis & $\begin{array}{c}\text { Age } \\
(y)\end{array}$ & $\begin{array}{c}\text { Weight } \\
(\mathrm{kg})\end{array}$ & $\begin{array}{c}\text { BSA } \\
\left(\mathrm{m}^{2}\right)\end{array}$ & $\begin{array}{c}\text { XCT } \\
(\mathrm{min})\end{array}$ & $\begin{array}{c}\text { Temperature } \\
\left({ }^{\circ} \mathrm{C}\right)\end{array}$ \\
\hline 1 & T21, VSD & 0.66 & 5.9 & 0.30 & 50 & 25 \\
2 & VSD & 0.64 & 7.5 & 0.38 & 41 & 30 \\
3 & VSD & 0.42 & 5.3 & 0.30 & 41 & 28 \\
4 & AoPW, VSD & 0.23 & 4.4 & 0.27 & 31 & 30 \\
5 & T21, AVSD & 0.64 & 4.6 & 0.25 & 81 & 18 \\
6 & VSD & 0.26 & 5.9 & 0.30 & 38 & 25 \\
7 & T21, AVSD & 0.64 & 4.8 & 0.27 & 35 & 24 \\
8 & T21, AVSD & 0.23 & 4.3 & 0.25 & 92 & 25 \\
9 & VSD & 0.26 & 5.1 & 0.30 & 42 & 30 \\
10 & T21, VSD, PDA & 0.56 & 4.8 & 0.27 & 33 & 28 \\
11 & T21, VSD & 0.82 & 7.5 & 0.38 & 34 & 30 \\
12 & VSD & 0.09 & 3.9 & 0.25 & 61 & 25 \\
13 & T21, AVSD & 0.10 & 3.7 & 0.24 & 78 & 25 \\
14 & T21, AVSD & 0.10 & 6.5 & 0.32 & 70 & 25 \\
15 & MVR & 0.31 & 4.8 & 0.30 & 79 & 25 \\
Group 1, ventilation $<2$ d & & $0.53 \pm 0.62$ & $5.7 \pm 1.9$ & $0.31 \pm 0.7$ & $49 \pm 21$ & $26.8 \pm 2.6$ \\
Group 2, ventilation $>2$ d & & $0.39 \pm 0.29$ & $5.4 \pm 1.4$ & $0.30 \pm 0.05$ & $61 \pm 22$ & $24.0 \pm 5.0$ \\
$P$ value (group 1 vs 2) & & .52 & .71 & .73 & .39 & .16
\end{tabular}

$B S A$, Body surface area; XCT, crossclamp time; Temperature, lowest temperature during CPB; Dex, single dose of dexamethasone given during CPB; Dopa, maximum dopamine $\left(\mu \mathrm{g} \cdot \mathrm{kg}^{-1} \cdot \mathrm{min}^{-1}\right)$ during postoperative course; $T 21$, trisomy 21 ; VSD, ventricular septal defect; AoPW, aortopulmonary window; AVSD, atrioventricular septal defect; $P D A$, patent ductus arteriosus; $M V R$, mitral valve replacement.

procedures at an earlier age and the development of improved strategies to manage the PVR in the postoperative period have led to the suggestion that the effect of postoperative elevation of PVR has become a relatively unimportant element of contemporary postoperative care. In this study we analyzed the relationship between pulmonary endothelial dysfunction, PVR, and clinical outcome in children at risk of pulmonary hypertension after operations requiring $\mathrm{CPB}$.

\section{Methods}

Patients. The study was approved by the Hospital Research Ethics Committee, and written informed consent was obtained from the parents of each child. All patients underwent surgical correction of the cardiac malformation with the use of low-flow hypothermic CPB and conventional ultrafiltration. Dexamethasone was added to the priming solution at the surgeon's discretion (Table I). Patients at risk for postoperative pulmonary hypertension were studied immediately after the heart operation in the intensive care unit. All patients were sedated, mechanically ventilated, and paralyzed (with vecuronium, midazolam, and morphine) throughout the study. They were intubated with a cuffed endotracheal tube (Mallinckrodt, Inc, St Louis, Mo) to exclude any respiratory gas leaks. Volume-controlled ventilation was delivered with a Siemens $900 \mathrm{C}$ ventilator (Siemens AG, Munich, Germany).

The study protocol was instituted 1 to 2 hours after CPB. This delay allowed for sufficient time for central rewarming, adjustment of sedation and inotropic agents, and tracheal suc- tioning after transfer to the pediatric intensive care unit. Residual lesions, such as intracardiac shunts, or significant atrioventricular valve dysfunction were excluded by means of echocardiography. Thereafter, further handling or therapeutic intervention during the study protocol was minimized. The cuff of the endotracheal tube was inflated with a pressure below the systemic diastolic blood pressure for the duration of the study protocol, during which continuous monitoring of hemodynamic pressures, surface electrocardiography, pulse oxymetry, and end-tidal carbon dioxide concentration (see below) was performed.

Special metabolic and hemodynamic measurements. Oxygen consumption (in milliliters per kilogram per minute) was continuously determined by means of respiratory mass spectrometry with the mixed expirate inert gas dilution method and our previously described modification for use in patients requiring assisted ventilation., ${ }^{3,4}$ Special care was taken to detect and exclude any air leaks or carbon dioxide contamination of the monitoring and ventilatory circuits. The mass spectrometer was calibrated directly before the study and then every 30 minutes to exclude any measurement drift.

Systemic arterial and pulmonary arterial pressures, as well as right and left atrial pressures, were measured, and blood samples were taken from the pulmonary artery and the left atrium. The partial pressures for oxygen and carbon dioxide and hemoglobin saturation were measured by using the spectral absorption method (Chiron 270 CO-Oximeter; Chiron Corporation, Emeryville, Calif), and the arteriovenous oxygen content difference (in milliliters per liter) and cardiac output (with the Fick principle; oxygen consumption/arteriovenous oxygen content difference), were calculated. PVR (ie, 


\begin{tabular}{|c|c|c|c|c|c|c|}
\hline $\begin{array}{l}\text { Dex } \\
(m g)\end{array}$ & $\begin{array}{l}C P B \\
(\min )\end{array}$ & $\begin{array}{c}\text { Ventilation } \\
\text { (d) }\end{array}$ & $\begin{array}{c}\text { Dopamine } \\
\left(\mu \mathrm{g} \cdot \mathrm{kg}^{-1} \cdot \mathrm{min}^{-1}\right)\end{array}$ & $\begin{array}{c}\text { Maximum } P V R \\
\left(W U \cdot m^{2}\right)\end{array}$ & $\begin{array}{c}\text { Minimum } P V R \\
\quad\left(W U \cdot m^{2}\right)\end{array}$ & $\begin{array}{c}\text { Fall in PVR } \\
\text { (\%) }\end{array}$ \\
\hline- & 147 & 1.74 & 4 & 7.4 & 6.1 & 82 \\
\hline- & 60 & 1.12 & 5 & 14.4 & 5.4 & 38 \\
\hline- & 57 & 2.50 & 2 & 15.3 & 5.3 & 34 \\
\hline 124 & 50 & 0.88 & 3 & 8.5 & 3.5 & 41 \\
\hline 121 & 117 & 14.99 & 7 & 15.8 & 12.9 & 84 \\
\hline - & 64 & 0.87 & 2 & 5.6 & 2.7 & 48 \\
\hline- & 60 & 0.92 & 5 & 3.4 & 1.6 & 47 \\
\hline 125 & 120 & 0.99 & 5 & 12.4 & 3.5 & 28 \\
\hline- & 65 & 0.95 & 2 & 8.0 & 5.7 & 71 \\
\hline 150 & 56 & 1.75 & 3 & 8.7 & 4.3 & 50 \\
\hline- & 49 & 5.50 & 4 & 14.1 & 7.6 & 54 \\
\hline 118 & 95 & 1.89 & 5 & 13.8 & 5.6 & 41 \\
\hline 100 & 112 & 7.94 & 7 & 21.6 & 13.9 & 64 \\
\hline 192 & 107 & 3.96 & 2 & 6.1 & 3.6 & 59 \\
\hline - & 120 & 14.69 & 5 & 21.7 & 8.9 & 41 \\
\hline $129 \pm 14$ & $79 \pm 34$ & $1.23 \pm 0.43$ & $3.4 \pm 1.8$ & $9.1 \pm 3.7$ & $4.3 \pm 1.6$ & $50 \pm 17$ \\
\hline $142 \pm 40$ & $94 \pm 32$ & $8.26 \pm 5.41$ & $4.5 \pm 2.3$ & $15.8 \pm 5.8$ & $8.6 \pm 4.1$ & $55 \pm 17$ \\
\hline .59 & .43 & .002 & .33 & .017 & .012 & .52 \\
\hline
\end{tabular}

in millimeters of mercury per liter per minute) and PVR index (ie, PVR times square meter) were derived from the transpulmonary pressure gradient and reported in Wood units (WU) indexed to body surface area (WU times square meter).

Protocol for evaluation of PVR. The study protocol was instituted after a cardiorespiratory steady state was confirmed during 5 to 10 minutes of monitoring. Measurements of oxygen consumption, cardiac output, and hemodynamic pressures began at baseline during ventilation with low fraction of inspired oxygen $\left(\mathrm{FIO}_{2}\right.$; range, 0.21-0.35) and were then made at the steady state value during the last 2 minutes of each new condition:

1. Ventilation in increased oxygen $\left(\mathrm{FIO}_{2}\right.$ of 0.65$)$, which was continued to the end of the protocol to obviate the possible confounding effects of alveolar hypoxia

2. Infusion (intravenous) of L-arginine (Fresenius, Bad Homburg, Germany), $15 \mathrm{mg} \cdot \mathrm{kg}^{-1} \cdot \mathrm{min}^{-1}$, which was continued to the end of the protocol as the substrate for endogenous nitric oxide $(\mathrm{NO})$ production

3. Infusion (intravenous) of substance $P$ (Clinalfa AG, Laeufelfingen, Switzerland), $1 \mathrm{pmol} \cdot \mathrm{kg}^{-1} \cdot \mathrm{min}^{-1}$, which was continued to the end of the protocol to stimulate endothelial NO production

4. Inhalation of NO (The BOC Group, Windlesham, Surrey, United Kingdom), 20 parts per million, which was continued to the end of the protocol to provide direct pulmonary vascular smooth muscle relaxation

Postoperative mechanical ventilation. Postoperative ventilation was used as an index of postoperative recovery and was measured as the time in hours between arrival at the intensive care unit and successful extubation. All medica- tions, including inhaled NO, were stopped at the end of the study protocol. In those requiring therapeutic manipulation of PVR, sedation, and paralysis were continued or reinstituted, and intermittent positive-pressure ventilation was adjusted to optimize ventilation. Where necessary (see "Results" section), inhaled NO was reinstituted (5-20 ppm) by the clinical care providers. Subsequent weaning from ventilation with inhaled NO was performed by gradually reducing inhaled NO to 1 to 2 ppm before withdrawal, while transiently receiving increased $\mathrm{FIO}_{2}$ (0.6-1.0). Subsequently, sedation was reduced, and ventilatory settings were gradually reduced as appropriate for ventilatory weaning.

Statistical analysis. All data are expressed as means \pm SD. A repeated-measures analysis of variance was used to analyze serial hemodynamic and metabolic data over time, and a post hoc paired $t$ test with Bonferroni correction was applied when appropriate to evaluate for significant differences between conditions and individual time points.

\section{Results}

Patients. Fifteen infants (mean age, 0.53 years; median age, 0.31 years; mean weight, $5.6 \mathrm{~kg}$; median weight, $5.1 \mathrm{~kg}$ ), all but one with intracardiac shunt and at risk of pulmonary hypertension, were studied (Table I). They all underwent corrective cardiac operations involving CPB (range, 49-147 minutes; median, 65 minutes) with a minimum temperature of $18^{\circ} \mathrm{C}$ to $30^{\circ} \mathrm{C}$ (median, $25^{\circ} \mathrm{C}$ ). Hemodynamic measurements at the start of the protocol, including metabolic variables, 
Table II. Baseline gas exchange and hemodynamic data

\begin{tabular}{lccc}
\hline Variable & Group 1 (mean $\pm \mathrm{SD})$ & Group 2 $($ mean $\pm S D)$ & P value \\
\hline Systemic arterial pressure $(\mathrm{mm} \mathrm{Hg})$ & $60 \pm 7$ & $60 \pm 6$ & .92 \\
Pulmonary arterial pressure $(\mathrm{mm} \mathrm{Hg})$ & $20 \pm 5$ & $26 \pm 8$ & .75 \\
Arterial oxygen partial pressure $(\mathrm{kPa})$ & & & \\
$\mathrm{FiO}_{2}=0.21$ & $9.6 \pm 2.1$ & $8.9 \pm 2.2$ & .89 \\
$\mathrm{FIO}_{2}=0.65$ & $32.4 \pm 6.3$ & $25.8 \pm 10.1$ & $<.01$ \\
$\mathrm{~V} \mathrm{O}_{2}\left(\mathrm{~mL} \cdot \mathrm{min}^{-1} \cdot \mathrm{m}^{-2}\right)$ & $135 \pm 30$ & $139 \pm 47$ & .68 \\
$\mathrm{Cardiac}_{\text {index }}\left(\mathrm{L} \cdot \mathrm{min}^{-1} \cdot \mathrm{m}^{-2}\right)$ & $2.65 \pm 1.27$ & $1.98 \pm 1.29$ & $<.05$ \\
$\mathrm{DO}_{2}\left(\mathrm{~mL} \cdot \mathrm{min}^{-1} \cdot \mathrm{m}^{-2}\right)$ & $407 \pm 173$ & $292 \pm 134$ & $<.01$ \\
$\mathrm{VO}_{2} / \mathrm{Do}$ & $\mathrm{ratio}(\%)$ & $51 \pm 12$ & $<.01$ \\
$\mathrm{PVR}$ index $\left(\mathrm{WU} \cdot \mathrm{m}^{2}\right)$ & $37 \pm 13$ & $15.7 \pm 5.7$ & $<.01$ \\
\hline
\end{tabular}

$\mathrm{NS}$, Not significant; $\dot{V} \mathrm{O}_{2}$, oxygen consumption; $\mathrm{Do}_{2}$, oxygen delivery.

were in the normal reported range for this situation, ${ }^{5}$ with the exception of increased pulmonary artery pressures, decreased cardiac output, and increased PVR in all patients (Table II). The median time from return to the intensive care unit until successful extubation was 1.75 days (range, 0.86-14.9 days).

Postoperative course. There were 9 patients (group 1) with an intubation time of less than 2 days (median, 0.99 days), leaving 6 patients (group 2) with prolonged mechanical ventilation (median, 6.7 days). Although $\mathrm{CPB}$ time, dexamethasone dose at $\mathrm{CPB}$, and necessary inotropic support until extubation in both groups were not statistically different (Table I), there was a correlation between the length of CPB time and the duration of ventilatory support time in group 2 patients $\left(r^{2}=\right.$ $0.48, P<.01$ ). Three patients (patients 5, 11, and 15) received NO for pulmonary hypertension crises (ie, an acute rise in pulmonary artery pressure associated with desaturation, systemic hypotension, and ventilatory difficulty caused by still lungs in 2 patients), and the remainder required prolonged sedation and ventilation to prevent pulmonary hypertension associated with wakefulness, tracheal suctioning-physiotherapy, or weaning. Two patients (patients 5 and 15) had additional signs of multiorgan failure and capillary leak, and 2 (patients 5 and 13) had pulmonary atelectasis and infection. Neither the presence of trisomy 21 nor treatment with steroids during CPB caused a significant difference in the response of the pulmonary vasculature or ventilatory time.

Study protocol. During the study protocol, arterial $\mathrm{PCO}_{2}$ or blood $\mathrm{pH}$ did not change. Systemic arterial pressure fell in response to the systemic infusion of substance P (Fig 1), but no patient required clinical intervention. After the application of oxygen, pulmonary artery pressure fell in group 1 patients and continued to do so in the subsequent steps of the study pro- tocol, whereas in patient group 2 a further fall in pulmonary artery pressure did not occur (Fig 1). The application of oxygen tended to expose a greater alveolar-arterial oxygen gradient in group 2 than in group 1. Although oxygen consumption was not different in either patient group, cardiac output (baseline, $1.97 \pm$ $1.27 \mathrm{~L} \cdot \mathrm{min}^{-1} \cdot \mathrm{m}^{-2}$ [group 2] vs $2.62 \pm 1.26 \mathrm{~L} \cdot \mathrm{min}^{-1}$ $\cdot \mathrm{m}^{-2}$ [group 1]; increasing during the study protocol to a maximum of $3.17 \pm 2.15 \mathrm{~L} \cdot \mathrm{min}^{-1} \cdot \mathrm{m}^{-2}$ [group 2] vs $4.13 \pm 2.53 \mathrm{~L} \cdot \mathrm{min}^{-1} \cdot \mathrm{m}^{-2}$ (group 1]) and therefore oxygen delivery (Fig 2) were significantly depressed in patient group 2 throughout the protocol. Oxygen extraction (oxygen consumption/delivery ratio) was greater at all protocol steps compared with that of patient group 1 (Fig 2).

$\mathrm{PVR}$ at baseline was $11.7 \pm 5.6 \mathrm{WU} \cdot \mathrm{m}^{2}$, which fell to $9.3 \pm 5.2 \mathrm{WU} \cdot \mathrm{m}^{2}$ at an $\mathrm{FIO}_{2}$ of 0.65 and then to its lowest level of $6.1 \pm 3.5 \mathrm{WU} \cdot \mathrm{m}^{2}$ during the further steps of the protocol. PVR in group 1 was significantly lower at all stages of the study protocol compared with that of group 2 (Fig 3), but the absolute and percentage change in PVR reduction during the study protocol was the same in both patient groups $(4.8 \pm 3.1$ vs $7.1 \pm 4.1$ WU $\cdot \mathrm{m}^{1}$ [body surface area], $P=.23 ; 50 \% \pm 17 \%$ vs $45 \% \pm 17 \%, P=.52$ ). The duration of ventilation did not correlate with cardiac index at baseline $\left(r^{2}=0.1, P=\right.$ .56), maximum cardiac index $\left(r^{2}=0.09, P=.89\right)$, baseline PVR $\left(r^{2}=0.208, P=.43\right)$, or the amount of PVR reduction during the protocol $\left(r^{2}=0.121, P=.51\right)$ but did correlate with PVR obtained after the infusion of substance $\mathrm{P}\left(r^{2}=0.55, P=.011\right)$ and the lowest PVR $\left(r^{2}\right.$ $=0.64, P<.01 ;$ Fig 4$)$.

\section{Discussion}

Pulmonary hypertension in children with congenital heart disease remains an important cause of postoperative morbidity and mortality. This study shows that the 


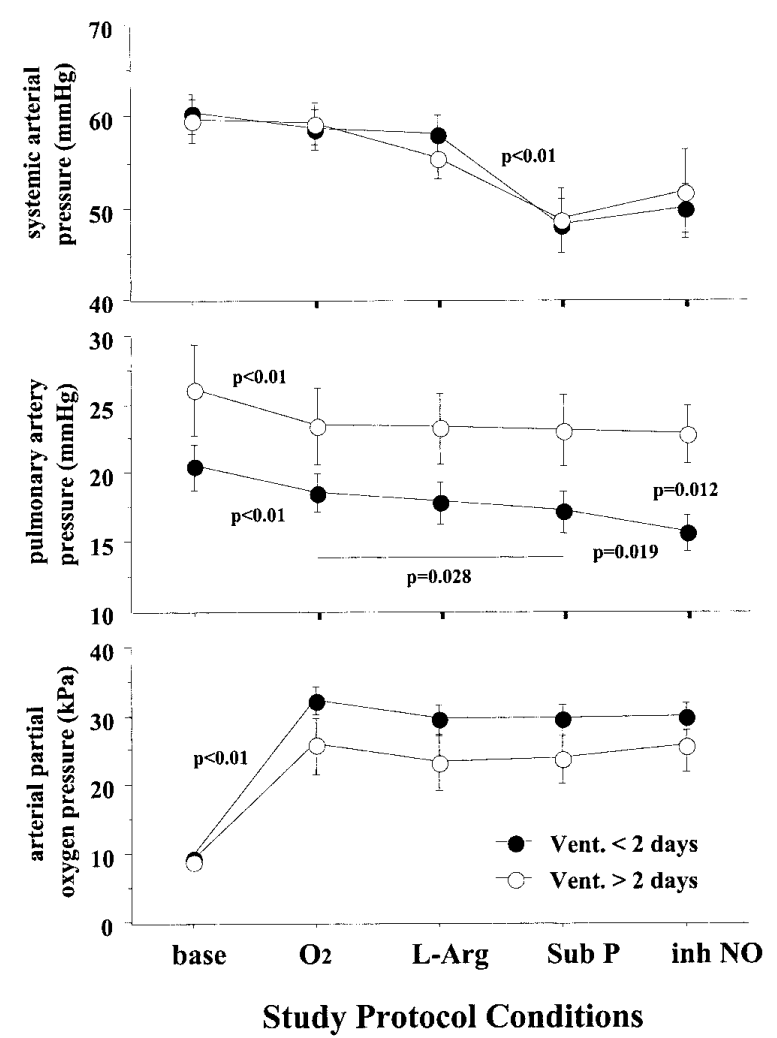

Fig 1. Hemodynamic and gas-exchange variables during study protocol. All values are displayed as means \pm SEM. Filled circles, Patients receiving ventilatory support for less than 2 postoperative days; open circles, patients receiving ventilatory support for more than 2 postoperative days; base, baseline; $\mathrm{O}_{2}$, inspired $\mathrm{FIO}_{2}$ of $0.65 ; \mathrm{L}-\mathrm{Arg}$, infusion of Larginine $\left(15 \mathrm{mg} \cdot \mathrm{kg}^{-1} \cdot \mathrm{min}^{-1}\right)$; Sub $P$, infusion of substance $\mathrm{P}\left(1 \mathrm{pmol} \cdot \mathrm{kg}^{-1} \cdot \mathrm{min}^{-1}\right)$; inh $\mathrm{NO}$, inhaled NO (20 ppm). Statistical significance of differences between patient groups is indicated as $P$ values; values are not significant where not indicated.

nonreversible element of postoperatively raised PVR, as measured in the immediate postoperative period, is directly correlated with the speed of postoperative recovery.

In our patients, postoperative baseline PVR was increased. Increased PVR in children with congenital heart disease, both preoperatively and postoperatively, has been ascribed to pulmonary endothelial dysfunction (ie, a failure of the endothelium to produce adequate amounts of $\mathrm{NO}$ in the presence of vascular smooth muscle cells, which are able to vasodilate on administration of exogenous sources of NO, such as nitroprusside or inhaled NO). ${ }^{6,7}$ Wessel and associates ${ }^{8}$ showed pulmonary endothelial dysfunction in a group of children after CPB operations for congenital heart disease by demonstrating the failure of pulmonary
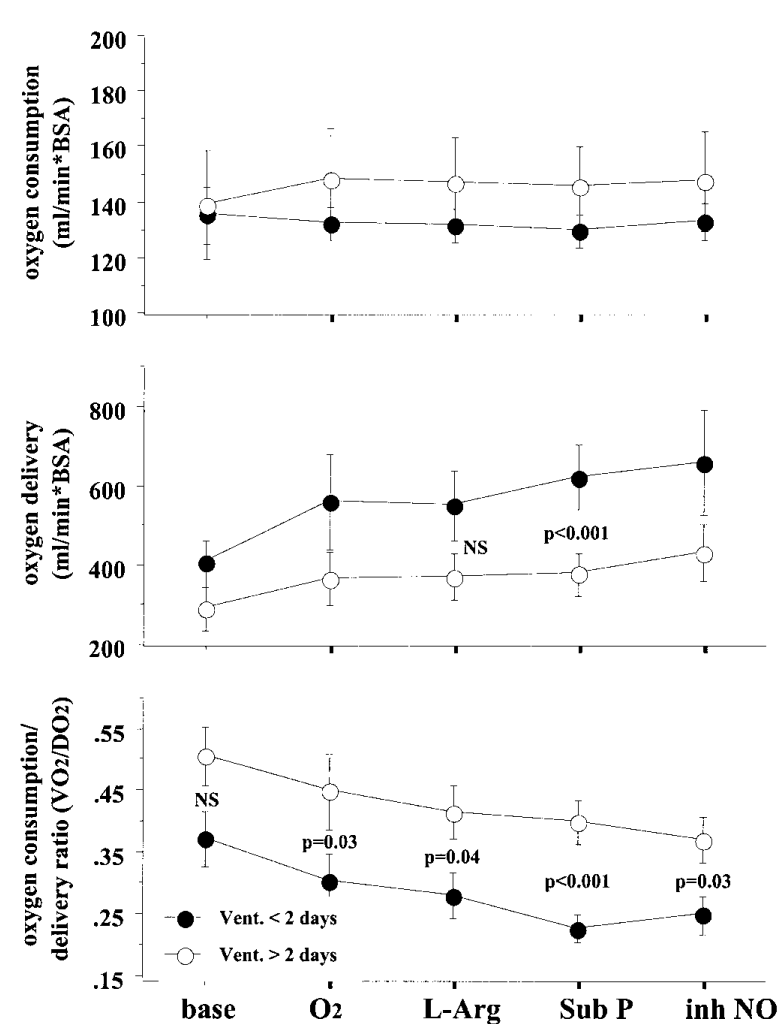

Fig 2. Oxygen consumption, oxygen delivery, and the ratio during study protocol. NS, Not significant. Other symbols and abbreviations are as shown in legend of Fig 1.

vasodilation in response to infused acetylcholine. However, in a previous study this pulmonary endothelial dysfunction was shown to be reversible by using substance $\mathrm{P}$, a non-G protein-dependent cellular pathway of endothelial NO production. ${ }^{1}$ However, regardless of the precise underlying mechanism, the current study showed that it is not pulmonary endothelial dysfunction and the amount of reversibly increased PVR associated with it that determined postoperative recovery in our patients but rather the residual PVR after supplementation of the L-arginine/NO pathway.

Increased PVR after CPB has been attributed to factors other than pulmonary endothelial dysfunction. Cardiac operations with CPB have direct adverse mechanical effects on the lung, resulting from deflation and manipulation during the operations (eg, infection), but may also be affected secondarily as part of a generalized inflammatory reaction. CPB causes activation of inflammatory pathways, leukocytes, and platelets, ${ }^{9,10}$ which results in the production of vasoconstrictive factors, such as thromboxanes and endothelins. ${ }^{11,12}$ Furthermore, preoperative pulmonary endothelial dys- 


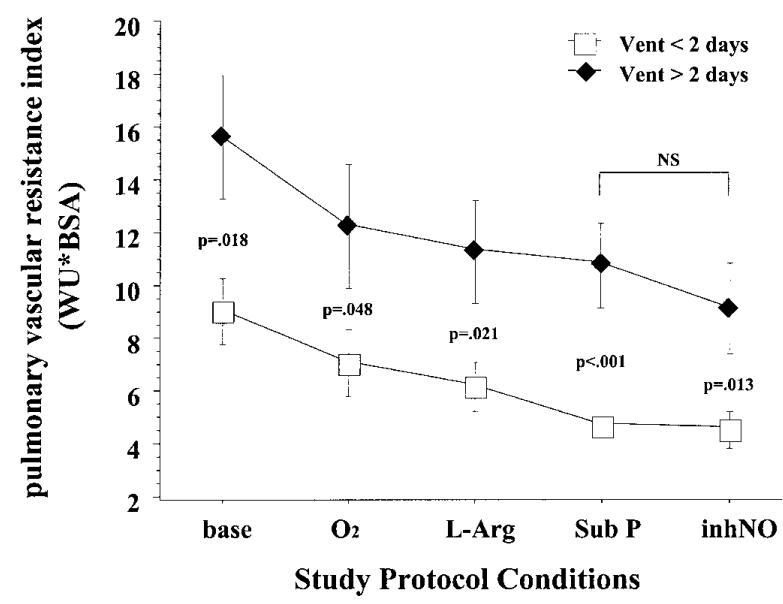

Fig 3. PVR during study protocol. NS, Not significant. Other symbols and abbreviations are as shown in legend of Fig 1.

function may amplify this injury to the pulmonary vascular bed. One study ${ }^{13}$ showed that the level of circulating endothelin, as well as the increase in PVR after $\mathrm{CPB}$, corresponded to the amount of preoperatively increased pulmonary blood flow, and another study showed that removal of postoperative endothelin by means of ultrafiltration resulted in a lower postoperative PVR. ${ }^{14}$ It remains true that patients with congenital heart disease being operated on according to contemporary surgical algorithms continue to sustain pulmonary damage both directly and as part of the whole-body inflammatory response to contact activation, hypothermia, hemodilution, and ischemia during $\mathrm{CPB}$. Although treatment strategies designed to reduce the specific pulmonary disease (eg, endothelin blockade and improved ventilatory management) may be beneficial, therapies directed toward suppression of the generalized systemic inflammatory response syndrome after $\mathrm{CPB}^{15}$ may be equally effective.

There were no clinical or echocardiographic indications of significant preoperative pulmonary vascular disease justifying catheterization, and therefore there were no preoperative PVR data to correlate with our postoperative findings. Furthermore, we were unable to correlate clinical improvement directly with changes or improvement of PVR. Nonetheless, our data remain a valid reflection of the relationship between early postoperative findings and subsequent outcomes.

\section{Summary}

We measured PVR in infants with intracardiac leftto-right shunting defects early after $\mathrm{CPB}$, differentiating those components of pulmonary endothelial dys-

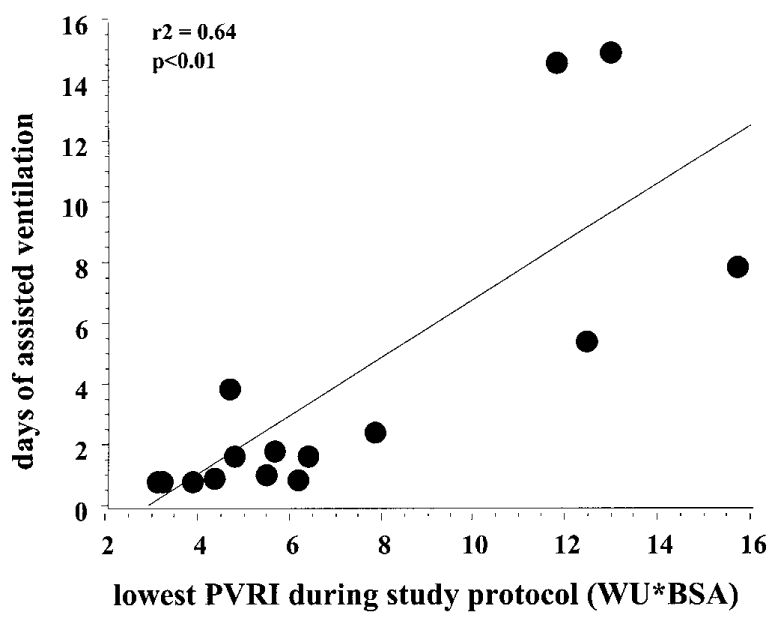

Fig 4. Correlation of days of assisted ventilation with lowest PVR achieved during the study protocol.

function that were restorable in the short term and those that were not. Increased PVR after maximal treatment of the L-arginine/NO pathway was significantly related to the need for postoperative mechanical ventilatory support. Additional strategies directed toward this nonreversible component of postoperative pulmonary vascular dysfunction may have significant clinical effect.

Received for publication Oct 17, 2000; revisions requested Nov 8, 2000; revisions received Nov 30, 2000; accepted for publication Dec 18, 2000.

Address for reprints: A. N. Redington, MD, Department of Paediatric Cardiology, Great Ormond Street Hospital, Great Ormond St, London WC1N 3JH, United Kingdom (E-mail: reding@attglobal.net).

\section{REFERENCES}

1. Schulze-Neick I, Penny DJ, Rigby ML, Morgan C, Kelleher A, Collins $\mathrm{P}$, et al. L-Arginine and substance $\mathrm{P}$ reverse the pulmonary endothelial dysfunction caused by congenital heart surgery. Circulation 1999;100:749-55.

2. Asimakopoulos G, Smith PL, Ratnatunga CP, Taylor KM. Lung injury and acute respiratory distress syndrome after cardiopulmonary bypass. Ann Thorac Surg 1999;68:1107-15.

3. Davies NJ, Shinebourne EA, Scallan MJ, Sopwith TA, Denison DM. Pulmonary vascular resistance in children with congenital heart disease. Thorax 1984;39:895-900.

4. Shekerdemian LS, Shore DF, Lincoln C, Bush A, Redington AN. Negative-pressure ventilation improves cardiac output after right heart surgery. Circulation 1996;94(Suppl):II-49-55.

5. Li J, Schulze-Neick I, Lincoln C, Shore D, Scallan M, Bush A, et al. Oxygen consumption after cardiopulmonary bypass surgery in children: determinants and implications. J Thorac Cardiovasc Surg 2000;119:525-33. 
6. Dinh-Xuan AT, Higenbottam TW, Clelland CA, Pepke-Zaba J, Cremona G, Butt AY, et al. Impairment of endotheliumdependent pulmonary-artery relaxation in chronic obstructive lung disease. N Engl J Med 1991;324:1539-47.

7. Celermajer DS, Cullen S, Deanfield JE. Impairment of endothelium-dependent pulmonary artery relaxation in children with congenital heart disease and abnormal pulmonary hemodynamics. Circulation 1993;87:440-6.

8. Wessel DL, Adatia I, Giglia TM, Thompson JE, Kulik TJ. Use of inhaled nitric oxide and acetylcholine in the evaluation of pulmonary hypertension and endothelial function after cardiopulmonary bypass. Circulation 1993;88:2128-38.

9. Hammerschmidt DE, Stroncek DF, Bowers TK, Lammi-Keefe CJ, Kurth DM, Ozalins A, et al. Complement activation and neutropenia occurring during cardiopulmonary bypass. J Thorac Cardiovasc Surg 1981;81:370-7.

10. Sonntag J, Dahnert I, Stiller B, Hetzer R, Lange PE. Complement and contact activation during cardiovascular operations in infants. Ann Thorac Surg 1998;65:525-31.

11. Adatia I, Barrow SE, Stratton PD, Ritter JM, Haworth SG. Effect of intracardiac repair on biosynthesis of thromboxane A2 and prostacyclin in children with a left to right shunt. Br Heart J 1994;72:452-6.

12. Bando K, Vijayaraghavan P, Turrentine MW, Sharp TG, Ensing GJ, Sekine Y, et al. Dynamic changes of endothelin-1, nitric oxide, and cyclic GMP in patients with congenital heart disease. Circulation 1997;96(Suppl):II-346-51.

13. Komai H, Adatia IT, Elliott MJ, de Leval MR, Haworth SG. Increased plasma levels of endothelin-1 after cardiopulmonary bypass in patients with pulmonary hypertension and congenital heart disease. J Thorac Cardiovasc Surg 1993;106:473-8.

14. Bando K, Vijay P, Turrentine MW, Sharp TG, Means LJ, Ensing GJ, et al. Dilutional and modified ultrafiltration reduces pulmonary hypertension after operations for congenital heart disease: a prospective randomized study. J Thorac Cardiovasc Surg 1998;115:517-27.

15. Hayashi Y, Sawa Y, Nishimura M, Tojo SJ, Ichikawa H, Satoh H, et al. P-selectin monoclonal antibody may attenuate the whole body inflammatory response induced by cardiopulmonary bypass. ASAIO J 2000;46:334-7.

\section{ON THE MOVE?}

Don't miss a single issue of the journal! To ensure prompt service when you change your address, please photocopy and complete the form below.

Please send your change of address notification at least six weeks before your move to ensure continued service. We regret we cannot guarantee replacement of issues missed due to late notification.

JOURNAL TITLE:

Fill in the title of the journal here.

\section{OLD ADDRESS:}

Affix the address label from a recent issue of the journal here.

\section{NEW ADDRESS: \\ Clearly print your new address here.}

Name

Address

City/State/ZIP
COPY AND MAIL THIS FORM TO:

Mosby

Subscription Customer Service

6277 Sea Harbor Dr

Orlando, FL 32887
OR FAX TO:

407-363-9661

N/ Mosby
OR PHONE:

800-654-2452

Outside the U.S., call

407-345-4000 